\title{
INFLUENCE OF NITROGEN GAS FLOW RATE ON THE MICROSTRUCTURAL AND MECHANICAL PROPERTIES OF TIN DEPOSITED CARBON STEEL SYNTHESIZED BY CAE PVD TECHNIQUE
}

\author{
A. Mubarak* ${ }^{*}$ E. Hamzah \\ Department of Materials Engineering, Faculty of Mechanical Engineering, \\ Universiti Teknologi Malaysia, 81310, Skudai, Johor, MALAYSIA
}

\begin{abstract}
M.R.M. Toff
Advanced Materials Research Center (AMREC), SIRIM Berhad, Jalan Hi-Tech 2/3, Kulim Hi-Tech Park, 09000 Kulim, Kedah, MALAYSIA
\end{abstract}

Received 01 December 2005

\begin{abstract}
This paper reports on the preparation of titanium nitride (TiN) thin films on carbon steel plates, using cathodic arc evaporation CAE PVD technique. We studied and discussed the effect of various nitrogen gas flow rates on microstructural and mechanical properties of TiN-coated carbon steel plates. The coating properties investigated in this work included the surface morphology, thickness of deposited coating, adhesion between the coating and substrate, coating composition, coating crystallography, hardness and surface characterization using a field emission scanning electron microscope (FE-SEM) with energy dispersive X-ray (EDX), Xray diffraction (XRD) with glazing incidence angle (GIA) technique, scratch tester, hardness testing machine, surface roughness tester and atomic force microscope (AFM). SEM analyses showed that all the films had columnar and dense structures with clearly defined substrate-film interfacial layers. The hardness of TiN-coated carbon steel was noted six times more than the hardness of uncoated one. An increase in nitrogen gas flow rate showed; decrease in the formation of macro-droplets, average roughness (Ra) and root-mean-square (RMS) values in CAE PVD technique. During XRD-GIA studies, it was observed that by increasing the nitrogen gas flow rate, the main peak $[1,1,1]$ shifted toward the lower angular position. Microhardness of TiN-coated carbon steel showed about six times increase in hardness than the uncoated one. Scratch tester results showed an average adhesion between the coating material and substrate. Thanks to the high resolution power could be observed that by increasing nitrogen gas flow rate there was percentage increase in the bearing ratio while percentage decrease in histogram.
\end{abstract}

Keywords: TiN, PVD, carbon steel, microstructure, hardness, surface roughness, adhesion

\section{INTRODUCTION}

The flexibility of coating processes, especially of the physical vapor deposition (PVD) method

\footnotetext{
* Corresponding author e-mail: mubarak60@hotmail.com
} 
well supported by the superior and controllable properties of modern coatings are responsible for the worldwide application of coated tools and many others. Coatings are widely used to improve the performance of industrial tools. The bond structure in transition metal nitrides consists of a mixture of covalent, metallic and ionic components, and is responsible for high hardness, excellent wear resistance as well as chemical inertness. The inclusion of macroparticles and the formation of pitting defects have been considered detrimental features of cathodic arc evaporated (CAE) coatings since the commercialization of these coatings for cutting-tool and corrosion-protection applications in the early 1980s [1, 2]. Over the years, various chamber configurations and deposition techniques have been developed to reduce the amount of coating defects [3 - 5]. Carbon steel is a material that can be used for various applications in medium scale industries. The main advantage of using carbon steel as base material, it is easy to available and cheaper in coat compared to other materials.

\section{EXPERIMENTAL DETAILS}

\subsection{Surface finish}

The samples used for this research are carbon steel (CS) plates (area $=225 \mathrm{~mm}^{2}, 3 \mathrm{~mm}$ thick). Before charging the samples for deposition, surface finish is one important parameter to optimize the coating properties. For this purpose, we used standard grinding and polishing methods to a surface mirror of $1 \mu \mathrm{m}$. Prior to coating, all samples are subjected to a standard ultrasonic cleaning in a commercial solvent for 30 minutes before they are positioned in the deposition chamber. Samples for SEM-interface study were cut using a Precision Cutter Accustom-50 Machine. These were mounted (cold mounting) and polished to a surface of $1 \mu \mathrm{m}$ and subjected to standard ultrasonic cleaning. Samples were then coated with Platinum (Pt) using a Polaron sputter coater for SEM surface and interface studies.

\subsection{Coating deposition}

In the present work, TiN coatings have been reactively deposited on CS plates (substrates) using a multi-source cathodic arc PVD coating system that comprises two vertically mounted titanium arc sources. The coating system used for this present study is made of Hauzer Techno Coating Europe BV, type HTC 625/2 ARC. Two pure titanium rectangular targets of dimensions 400 $\mathrm{mm} \times 130 \mathrm{~mm} \times 15 \mathrm{~mm}$ were installed on the opposite side of a rectangular deposition chamber. The CS substrates were then loaded into the vacuum chamber as shown in Fig. 1. The average distance between the high purity (>99.99 at. \%) arcs and the substrate holder was about $18 \mathrm{~cm}$. The turntable substrate holder was rotated continuously by its axis to provide a uniform coating and to form the desired phase; the rotation speed was set to $40 \%$. The chamber was evacuated to a pressure of $5 \times 10^{-6} \mathrm{mbar}$ and then back filled with nitrogen gas in the range of $10^{-3}$ mbar. The substrates were biased at a $-1000 \mathrm{~V}$ potential and subjected to ion-bombardment. It has been demonstrated that the ion bombardment favors local epitaxial film growth, which enhances adhesion between coating \& substrate [6]. During deposition, the substrates were biased with a dc power source to induce proper ion bombardment on the growing surface to assist the formation of desirable structure, grain size and film density. The delivery of gas was by manifolds located adjacent to the cathodes and gas pressure could be measured using Baratron and Penning gauges.

For the deposition of the TiN coatings, nitrogen was introduced into the coating chamber and single layer coatings were deposited at arc current of 100A (both Cathode). A constant nitrogen gas flow rate regulated by a mass flow controller was introduced into the chamber before arc ignition, during each experiment. A more detailed list of deposition process parameters is given in Table 1. 


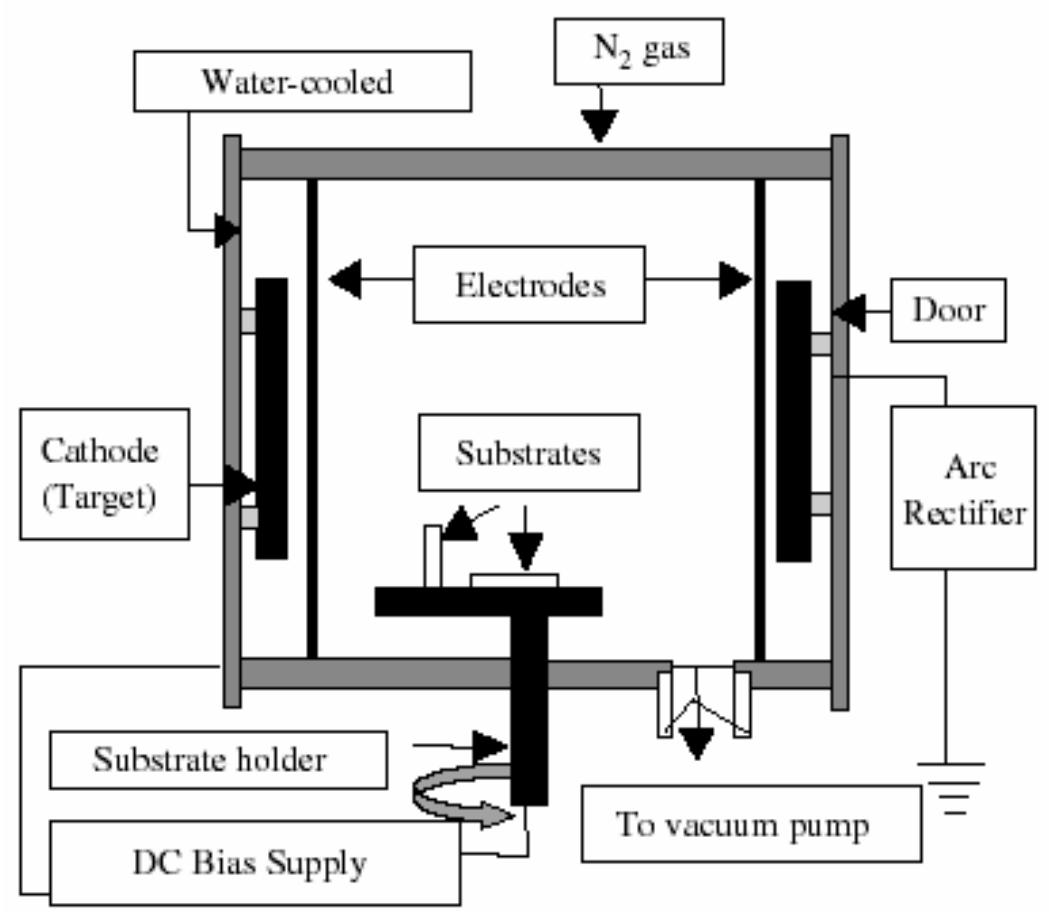

Fig. 1: A schematic diagram of the CAE PVD system

\subsection{Evaluation of coating properties}

The following quantitative and qualitative techniques were used to evaluate the coatings deposited on polished carbon steel substrates:

- Phase (structure) identification, d-spacing, crystal orientation of the as-deposited films was identified with an XRD (Bruker Model D8 Advance X-Ray Diffractrometer System) using GIA technique.

- Surface morphology and interface studies were done using FE-SEM (Model LEO-1525), which also enabled a measurement of macroparticle characteristics: size; shape; and distribution.

- The thickness of the coatings was measured using SEM via cross-sections.

- The adhesion between the coating and substrate was observed using SEM via cross-sections.

- The elemental composition of coated and uncoated samples was analyzed using EDX.

- The hardness of uncoated and coated samples were measured using a micro-Vickers hardness testing machine (Model-H31, Mitutoyo).

- The surface roughness of uncoated and coated samples was measured using a surface roughness tester (Model-Surftest SJ-301, Mitutoyo).

- Surface characterization of coated samples was done using AFM (Model: SPM-9500J2, Shimadzu Corporation).

- Adhesion; scratch test; critical load Lc $(\mathrm{N})$ were determined by optical observation of the scratch track (CSM-Instruments, REVETEST). 
Table 1: Deposition parameters

\begin{tabular}{lllll}
\hline Pre-bias & Pre-bias time & Bias voltage & Substrate temp. $\left({ }^{\mathbf{0}} \mathbf{C}\right)$ & $\mathbf{N}_{2}$ gas flow rates \\
\hline$-1000 \mathrm{~V}$ & 5 minutes & $-50 \mathrm{~V}$ & 250 & $100 \mathrm{sccm}$ \\
$-1000 \mathrm{~V}$ & 5 minutes & $-50 \mathrm{~V}$ & 250 & $150 \mathrm{sccm}$ \\
$-1000 \mathrm{~V}$ & 5 minutes & $-50 \mathrm{~V}$ & 250 & $200 \mathrm{sccm}$ \\
\hline
\end{tabular}

\section{RESULTS AND DISCUSSION}

\subsection{X-Ray diffraction (XRD) with grazing incidence angle (GIA)}

Conventional $\theta-2 \theta$ scanning is not suitable for characterizing thin films, because the X-ray path through the thin films is too short to produce adequate diffraction intensities relative to the substrate [7]. Phase and crystal structures of the as-deposited films were identified with an Xray diffractometer, using $\mathrm{CuK} \alpha$ radiation, $\lambda=0.15406 \mathrm{~nm}$ with a $\mathrm{Ni}$ filter, operated at $40 \mathrm{kV}$ and $40 \mathrm{~mA}$, and grazing angle of $1^{\circ}$. Scans were recorded in the $2 \theta$ ranges from 20 to 90 degrees, with a step size $0.020^{\circ}$ and a dwell time of 1 second. Since the path length of X-rays in a film is increased owing to the grazing incidence, the relative intensity associated with the film is enhanced while that of the substrate is decreased. The structure of the TiN film was identified as having a cubic B1 structure, and the nitrogen atoms occupy all the octahedral interstitial sites in the fcc metal lattice. According to the Hägg rule [8], the structure of the transition metal nitrides is determined by the ratio (r) of the atomic radius of nitrogen $\left(\mathrm{r}_{\mathrm{x}}\right)$ to the atomic radius of the transition metal $\left(r_{m e}\right), r=r_{x} / r_{m e}$. If $r$ is less than 0.59 , a simple structure such as $B 1$ or simple hexagonal would be formed. The atomic radius of nitrogen to titanium is 0.504 [8].

From Fig. 2, the prominent high intensity peak $[1,1,1]$ of titanium and nitrogen can clearly be seen, as an indication of desired coatings. The XRD pattern of as-deposited TiN film is shown in Fig. 2, at various nitrogen gas flow rates. The main peak $[1,1,1]$ in Fig. 2 showed a clear indication of fcc crystal structure and shifted to lower angular position with an increase in nitrogen gas flow rates. The shifting of main peak to lower angular position in TiN-coated CS plate basically indicates an increase in intrinsic stress, whereas the peaks like $[2,0,0]$ and $[2,2,0]$ showed the reflections from crystalline metallic titanium.

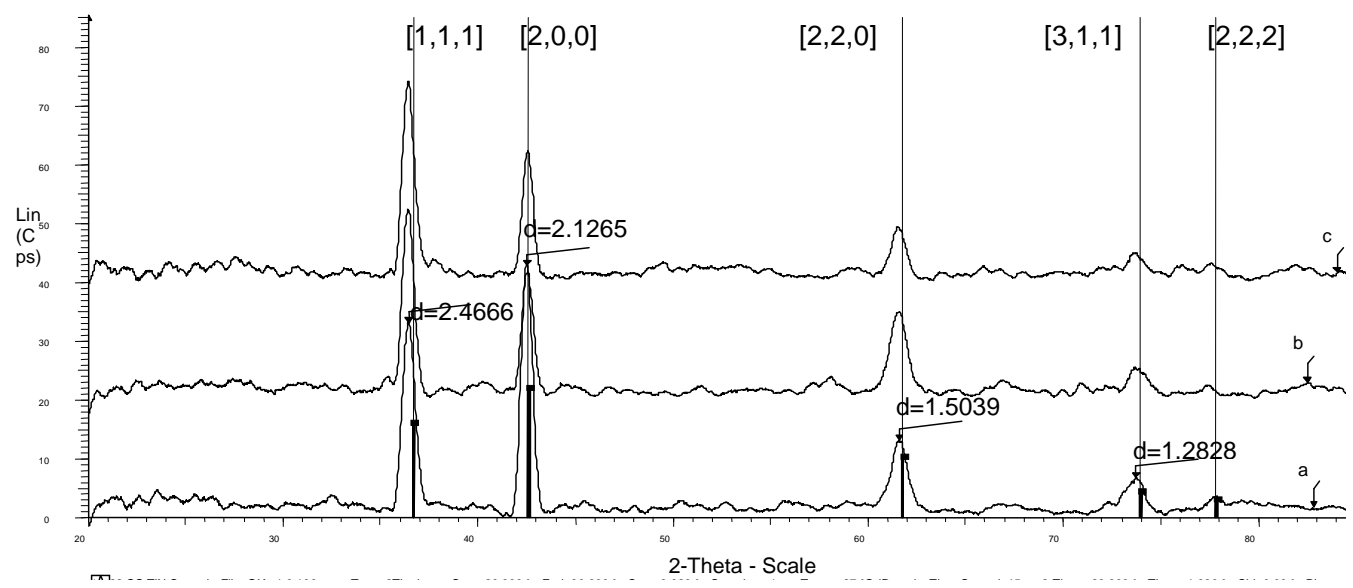

Fig. 2: XRD patterns of TiN films by GIA method at various nitrogen gas flow rates: (a) 100 sccm, (b) $150 \mathrm{sccm}$ and (c) $200 \mathrm{sccm}$ 


\subsection{Scanning electron microscope with energy dispersive X-ray (SEM/EDX)}

Surface morphology of the coatings was observed using a field emission scanning electron microscope (FE-SEM) model LEO-1525. SEM micrographs at nitrogen gas flow rates of 100 $\mathrm{sccm}$ and $200 \mathrm{sccm}$ are shown in Fig. 3. Increasing the partial pressure of the reactive gas during deposition can decrease the number of macroparticles in reactively CAE coatings [9 - 11]. It was noted that by increasing nitrogen gas flow rate, macrodroplets decreased (Figs. 3(a) and 3 (b)). In TiN deposition, the compound layer of TiN, which has been shown to form on the surface of the Ti cathodes, has a significantly higher melting point $\left(2030^{\circ} \mathrm{C}\right)$ compared with the $\mathrm{Ti}$ cathode $\left(1660^{\circ} \mathrm{C}\right)$ [12]. This has in turn been shown to reduce the number of $\mathrm{Ti}$ macroparticles deposited in subsequent TiN coatings $[12,13]$. The thickness of the deposited coating about $3.8 \mu \mathrm{m}$, and can be seen in Fig. 4 (a), whereas, the adhesion between the substrate and coating material can be seen in Fig. 4(b), which was dense and uniform with the substrate.

Gao Wei-Min et al. [14] extracted the thickness of the TiN coating from the experimental surface acoustic wave velocity dispersion curve by using an inverse fitting algorithm. The result of energy dispersive X-ray (EDX) analysis of deposited coating can be seen in Fig. 5 (a). In Fig. 5 (a), a deposited coating (TiN) can be seen clearly, as high intensity peaks. A small amount of carbon also migrated in coating material from the base material (substrate) during surface finish (Fig. 5 (a)).

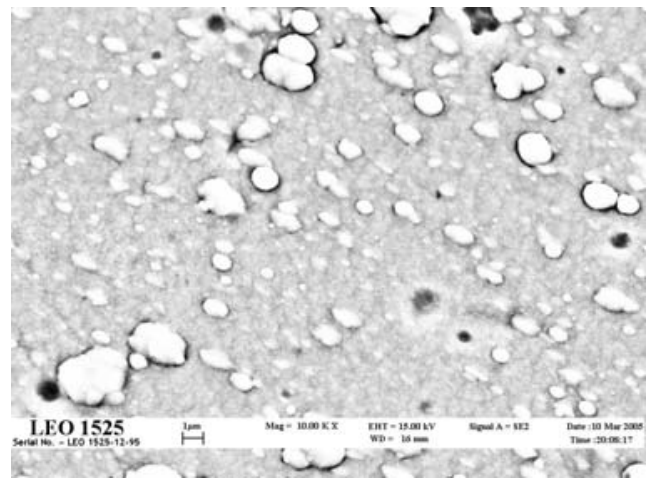

(a)

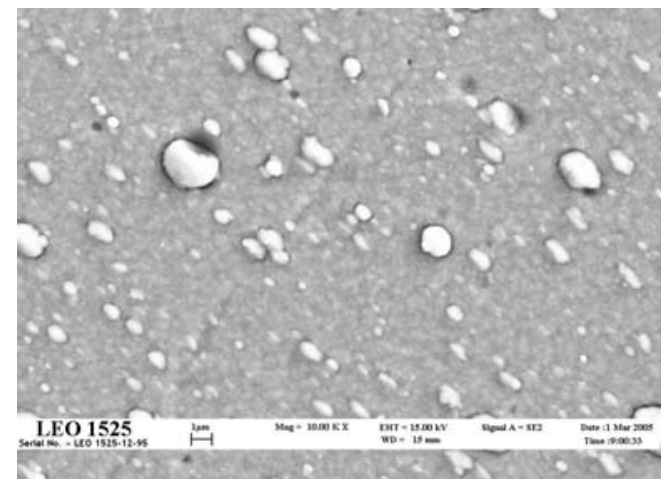

(b)

Fig. 3: SEM micrographs of TiN coating at nitrogen gas flow rates of (a) $100 \mathrm{sccm}$ and (b) $200 \mathrm{sccm}$

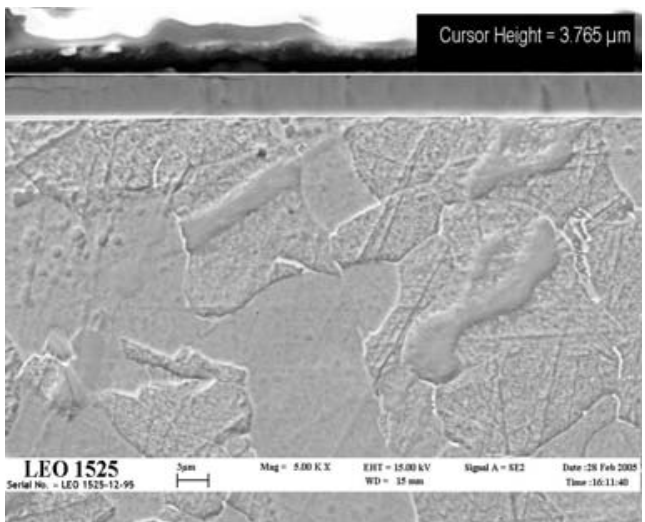

(a)

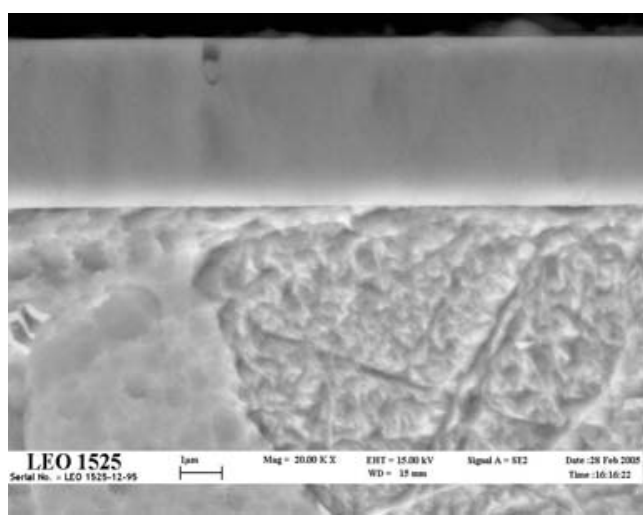

(b)

Fig. 4: SEM interface micrographs showing (a) thickness of deposited coating $\approx 3.8 \mu \mathrm{m}$ and (b) adhesion between TiN and CS 


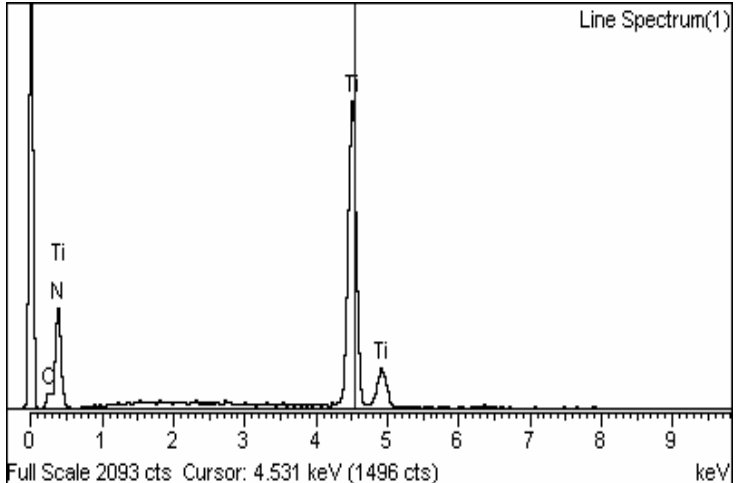

(a)

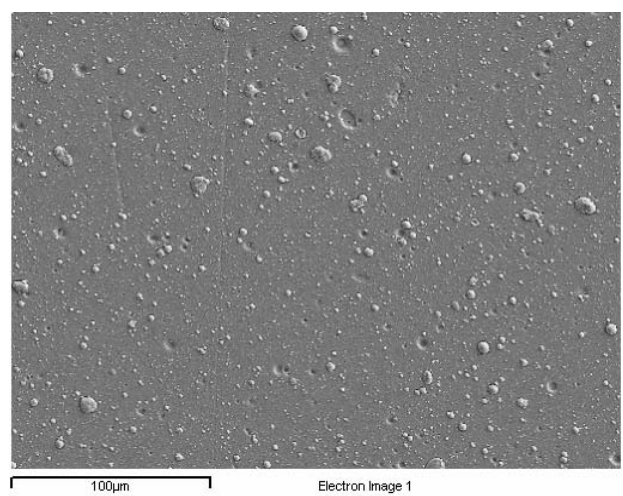

(b)

Fig. 5: Elemental composition analysis of (a) TiN coating and (b) Surface micrograph of TiN showing macro-droplets and pitting defects at nitrogen gas flow rate $200 \mathrm{sccm}$

\subsection{Hardness}

The easiest way to prepare superhard coatings is the application of energetic ion bombardment during the deposition, as by Musil [15 - 17]. Substrate hardness and coating hardness was measured using micro-Vickers hardness testing machine. Microhardness of the uncoated CS plate was about $155 \mathrm{HV}_{0.05}$. After being coated with TiN, the microhardness increased to about $945 \mathrm{HV}_{0.05}$ (at $\mathrm{N}_{2}$ gas flow rate of $200 \mathrm{sccm}$ ), which is about $600 \%$ the hardness of the uncoated one. The hardness enhancement results from a complex synergistic effect of the decrease of crystallite size, densification of grain boundaries, built in of compressive stress and formation of radiation damage (Frenkel pairs, etc.) upon energetic ion bombardment [18].

\subsection{Surface roughness}

The results of quantitative surface roughness tests on uncoated and coated CS plates are reported in Table 2. The most commonly-used parameters for characterizing the roughness of PVD coatings is the average roughness ( $\mathrm{Ra})[19,20]$, also known as arithmetic average (AA). It is calculated as the area between the roughness profile and its mean line, or the integral of the absolute value of the roughness profile height over the evaluation length. Using this parameter, the roughness of the CAE TiN-coated CS plates defined by the Ra parameter is within 0.21 $0.51 \mu \mathrm{m}$ range and is significantly higher than in the case of the uncoated polished sample i.e. $0.07 \mu \mathrm{m}$. The main limitation of $\mathrm{Ra}$ is that it gives no indication of the surface texture, namely macro-droplets and pitting defects that can have a significant influence on the performance of the coating, particularly for wear resistance applications. $\mathrm{Rz}$ and $\mathrm{Rq}$ indicate the average maximum height of the roughness profile and the root-mean-square (RMS) roughness of the profile.

Table 2: $\quad$ Surface roughness of CAE PVD using a surface roughness tester

\begin{tabular}{llll}
\hline $\mathbf{N}_{2}$ gas flow rates & $\begin{array}{l}\text { Ra (ISO 97, Gauss) } \\
\boldsymbol{\mu m}\end{array}$ & $\begin{array}{l}\text { Rz (ISO 97, Gauss) } \\
\boldsymbol{\mu m}\end{array}$ & $\begin{array}{l}\text { Rq (ISO 97, Gauss) } \\
\boldsymbol{\mu m}\end{array}$ \\
\hline uncoated & 0.07 & 1.18 & 0.12 \\
$200 \mathrm{sccm}$ & 0.21 & 3.00 & 0.32 \\
$150 \mathrm{sccm}$ & 0.28 & 3.20 & 0.42 \\
$100 \mathrm{sccm}$ & 0.51 & 4.13 & 0.69 \\
\hline
\end{tabular}


The surface roughness increase resulting from deposition of the TiN coatings should be attributed to the PVD process character-cathodic arc evaporation and occurrence of the characteristic micro-droplets, due to deposition of the pure titanium droplets, coming from the sputtered target, and pits developing due to the titanium microparticles dropping out, immediately after finishing the coating deposition process. Therefore, the surfaces of the coatings demonstrate inhomogeneities connected with shaped occurrences of the droplet shaped and elongated microparticles, originating probably from their sputtering when they hit the substrate surface during the coating deposition process [Fig. 5 (b)]. Harris et al. [21] calculated the roughness of the TiN Coatings on HSS twist Drill, and found that it increased from 0.104 to $0.116 \mu \mathrm{m}$ as the chamber pressure decreased from 1.2 to $0.1 \mathrm{~Pa}$. Golombek et al. [22] measured surface roughness Ra, parameter value $0.59 \mu \mathrm{m}$, TiN-coated cement carbides using the CAE technique.

\subsection{Atomic force microscopy (AFM)}

The scanning probe microscope (SPM) is the general name of a microscope which can observe surfaces at high magnification by scanning the sample surface while using a microprobe to detect whatever interaction is taking place. SPMs include the scanning tunneling microscope (STM) and the atomic force microscope (AFM). The AFM is a microscope that scans sample surface with a microtip (cantilever) to enable high-magnification observation of threedimensional forms. AFM analysis provided us the surface roughness as a function of the lateral length scale and an estimation of the columnar grain size. AFM is also suitable for quantitative study of surface roughness and scaling parameters [23]. The topography of the surface samples was observed using the scanning probe microscope (model SPM-9500J2, Shimadzu Corporation), with an AFM that was controlled via the Microsoft Window 95 OS. An optical microscope was coupled allowing the visualization of the region in which the AFM images will be taken. The standard scanning range enabled measurements of $30 \mu \mathrm{m}$ and up to a height of 5 $\mu \mathrm{m}$. Incidence strength and position of the laser beam on the detector could be discerned at a glance. Images were obtained by using a commercial $\mathrm{Si}_{3} \mathrm{~N}_{4}$ cantilever operating in contact mode. In the present work, AFM with contact mode has been used to investigate the modifications of TiN-coated CS plates at various nitrogen gas flow rates. Figure 6 shows three-dimensional (3D) images, which are clear indications of reduction of macrodroplets with an increase in nitrogen gas flow rate.

Table 3: Values of Surface Parameter of TiN coated CS at various nitrogen gas flow rates

\begin{tabular}{llll}
\hline Parameters & $\mathbf{1 0 0} \mathbf{~ s c c m}$ & $\mathbf{1 5 0} \mathbf{~ s c c m}$ & $\mathbf{2 0 0} \mathbf{~ s c c m}$ \\
\hline Length-X & $2.0 \mu \mathrm{m}$ & $2.0 \mu \mathrm{m}$ & $2.0 \mu \mathrm{m}$ \\
Length-Y & $2.0 \mu \mathrm{m}$ & $2.0 \mu \mathrm{m}$ & $2.0 \mu \mathrm{m}$ \\
Area & $4.0(\mu \mathrm{m})^{2}$ & $4.0(\mu \mathrm{m})^{2}$ & $4.0(\mu \mathrm{m})^{2}$ \\
$\mathrm{Ra}$ & $24.576 \mathrm{~nm}$ & $15.722 \mathrm{~nm}$ & $10.667 \mathrm{~nm}$ \\
$\mathrm{Ry}$ & $247.916 \mathrm{~nm}$ & $186.064 \mathrm{~nm}$ & $110.609 \mathrm{~nm}$ \\
$\mathrm{Rz}$ & $135.573 \mathrm{~nm}$ & $118.188 \mathrm{~nm}$ & $50.843 \mathrm{~nm}$ \\
$\mathrm{Rms}$ & $33.528 \mathrm{~nm}$ & $21.298 \mathrm{~nm}$ & $14.477 \mathrm{~nm}$ \\
$\mathrm{Rp}$ & $131.889 \mathrm{~nm}$ & $120.696 \mathrm{~nm}$ & $68.411 \mathrm{~nm}$ \\
$\mathrm{Rv}$ & $116.029 \mathrm{~nm}$ & $65.367 \mathrm{~nm}$ & $42.199 \mathrm{~nm}$ \\
\hline
\end{tabular}




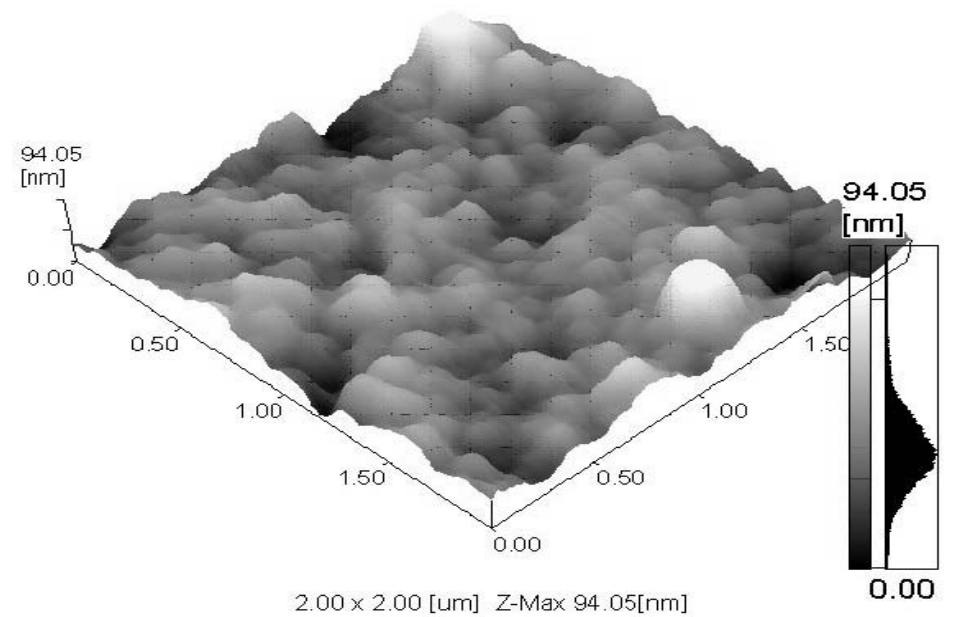

(a)

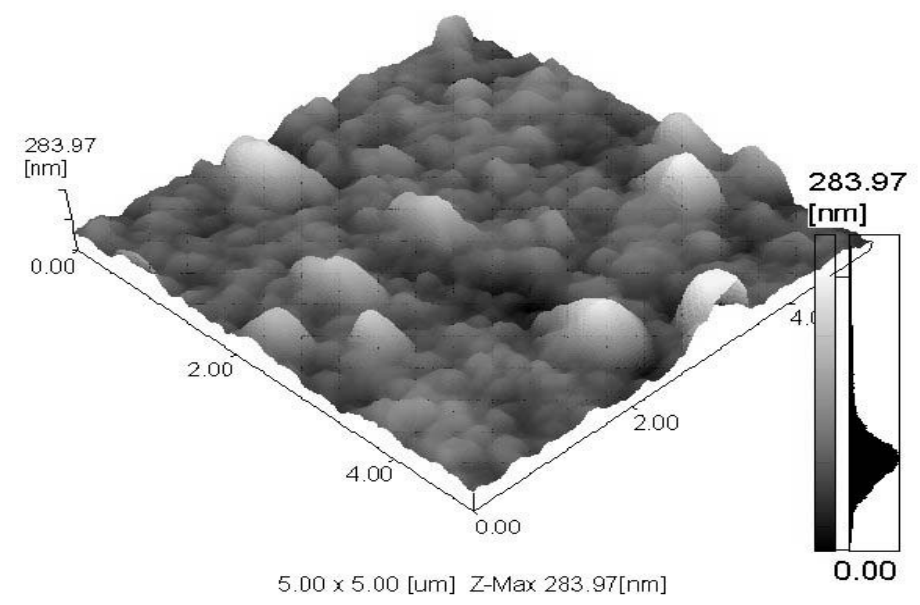

(b)

Fig. 6: $3 D$ AFM images of $10 \mu \mathrm{m} \times 10 \mu \mathrm{m}$ surface at nitrogen gas flow rate of (a) $150 \mathrm{sccm}$ and (b) $200 \mathrm{sccm}$

In Fig. 6, the grains were formed in peaks and valleys-island shaped particles and were clearly identified. It was noted from Table 3 that the value of Rms changed from $33.528 \mathrm{~nm}$ to 14.477 $\mathrm{nm}$, when the nitrogen gas flow rate increased from $100 \mathrm{sccm}$ to $200 \mathrm{sccm}$. Chico et al. [24] obtained a Rms of $0.98 \AA$ for the unimplanted surface and $1.92 \AA$ for the $\mathrm{N}$-implanted region in AISI 304 austenitic stainless steel.

Table 4: Topography information of TiN-coated carbon steel at various gas flow rates

\begin{tabular}{llllllll}
\hline $\begin{array}{l}\mathbf{N}_{2} \text { gas } \\
\text { flow rate } \\
(\mathbf{s c c m})\end{array}$ & $\begin{array}{l}\text { Range } \\
\text { cursor (nm) }\end{array}$ & $\begin{array}{l}\text { Surface } \\
\text { area } \\
(\mu \mathbf{m})^{2}\end{array}$ & $\begin{array}{l}\text { Area } \\
(\mu \mathbf{m})^{2}\end{array}$ & $\begin{array}{l}\text { Volume } \\
(\mu \mathbf{m})^{3}\end{array}$ & $\begin{array}{l}\text { Height } \\
(\mathbf{n m})\end{array}$ & $\begin{array}{l}\text { Histogram } \\
(\%)\end{array}$ & $\begin{array}{l}\text { Bearing } \\
\text { ratio }(\%)\end{array}$ \\
\hline 100 & $247.48-0.00$ & 4.29 & 4.0 & 0.47 & 124.0 & 0.55 & 65.0 \\
150 & $110.68-0.00$ & 4.15 & 4.0 & 0.17 & 55.45 & 0.31 & 86.75 \\
200 & $186.1-0.00$ & 4.26 & 4.0 & 0.26 & 93.23 & 0.29 & 90.68 \\
\hline
\end{tabular}



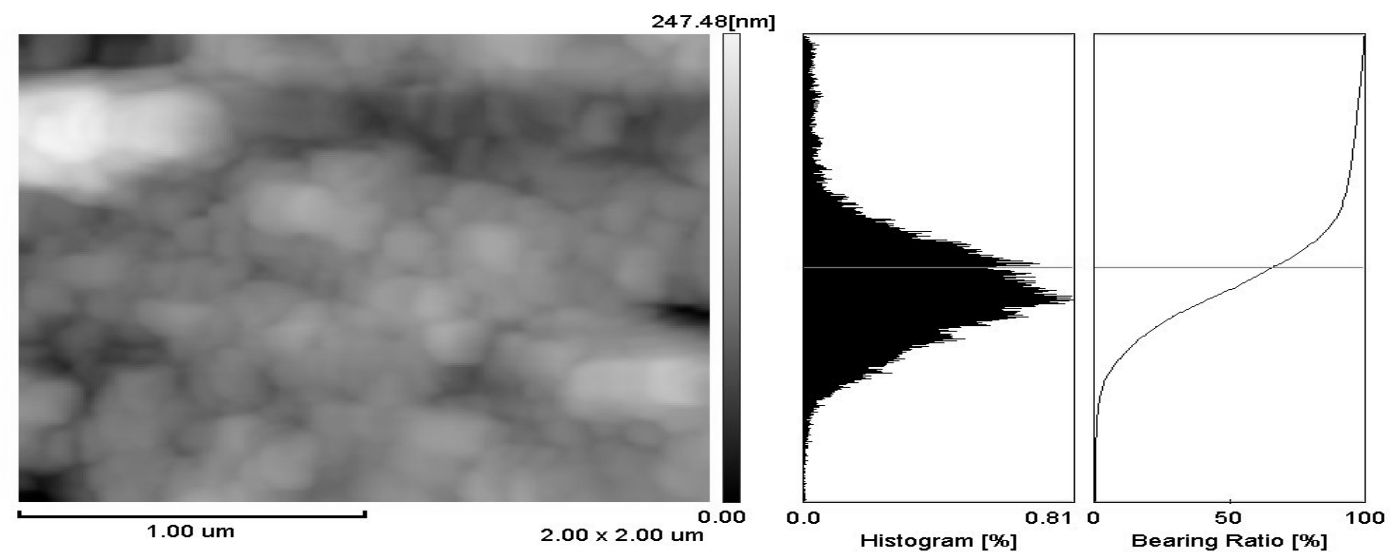

(a)
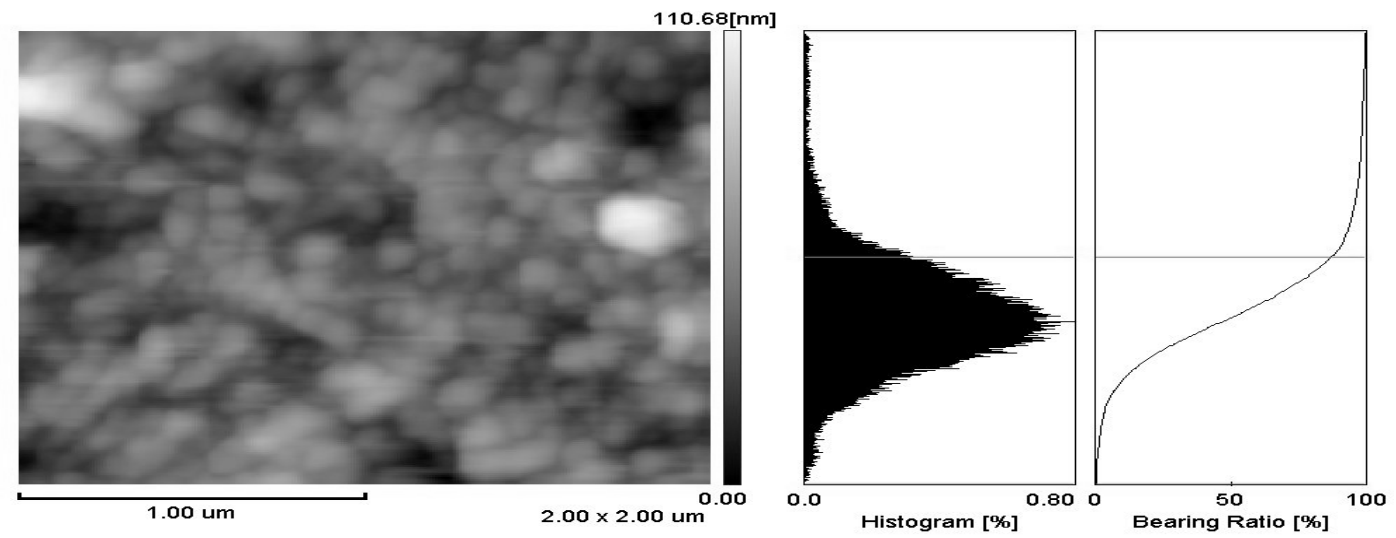

(b)
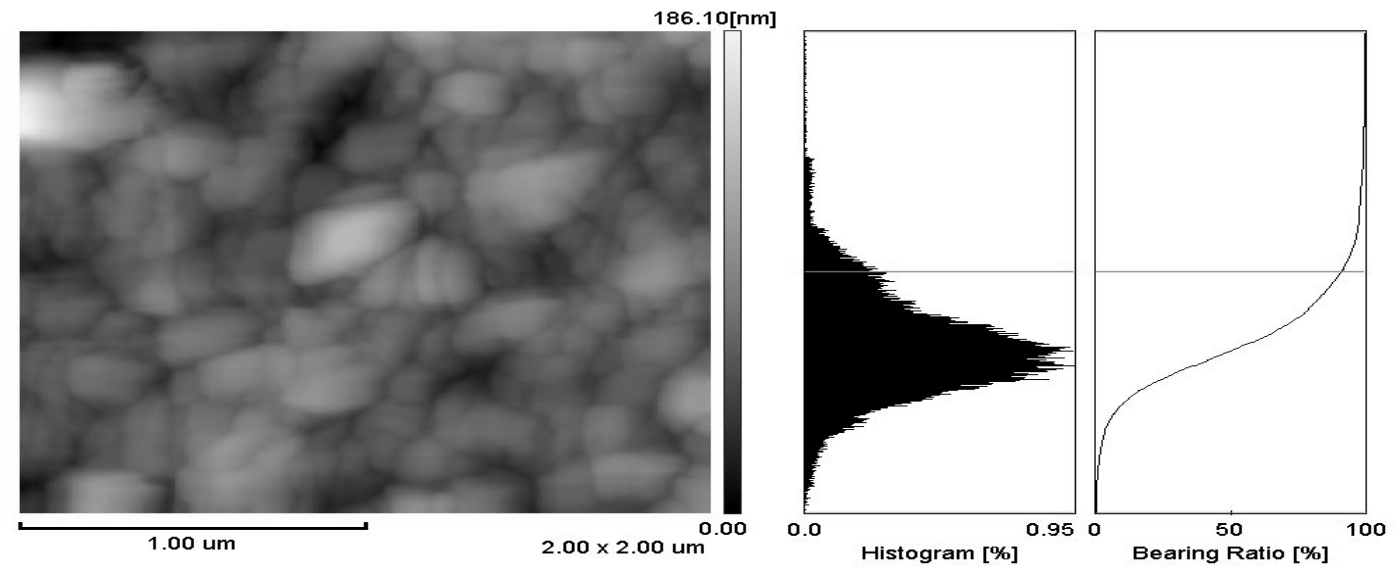

(c)

Fig. 7: Topography images showing qualitative analysis (bearing ratio and histogram) at (a) $100 \mathrm{sccm}$; (b) $150 \mathrm{sccm}$; (c) $200 \mathrm{sccm}$

From Table 4, as we increase nitrogen gas flow rate during deposition, increase in bearing ratio 
(\%) while decrease in histogram (\%) was noted. Detail information about line profile can be seen in Fig. 8.
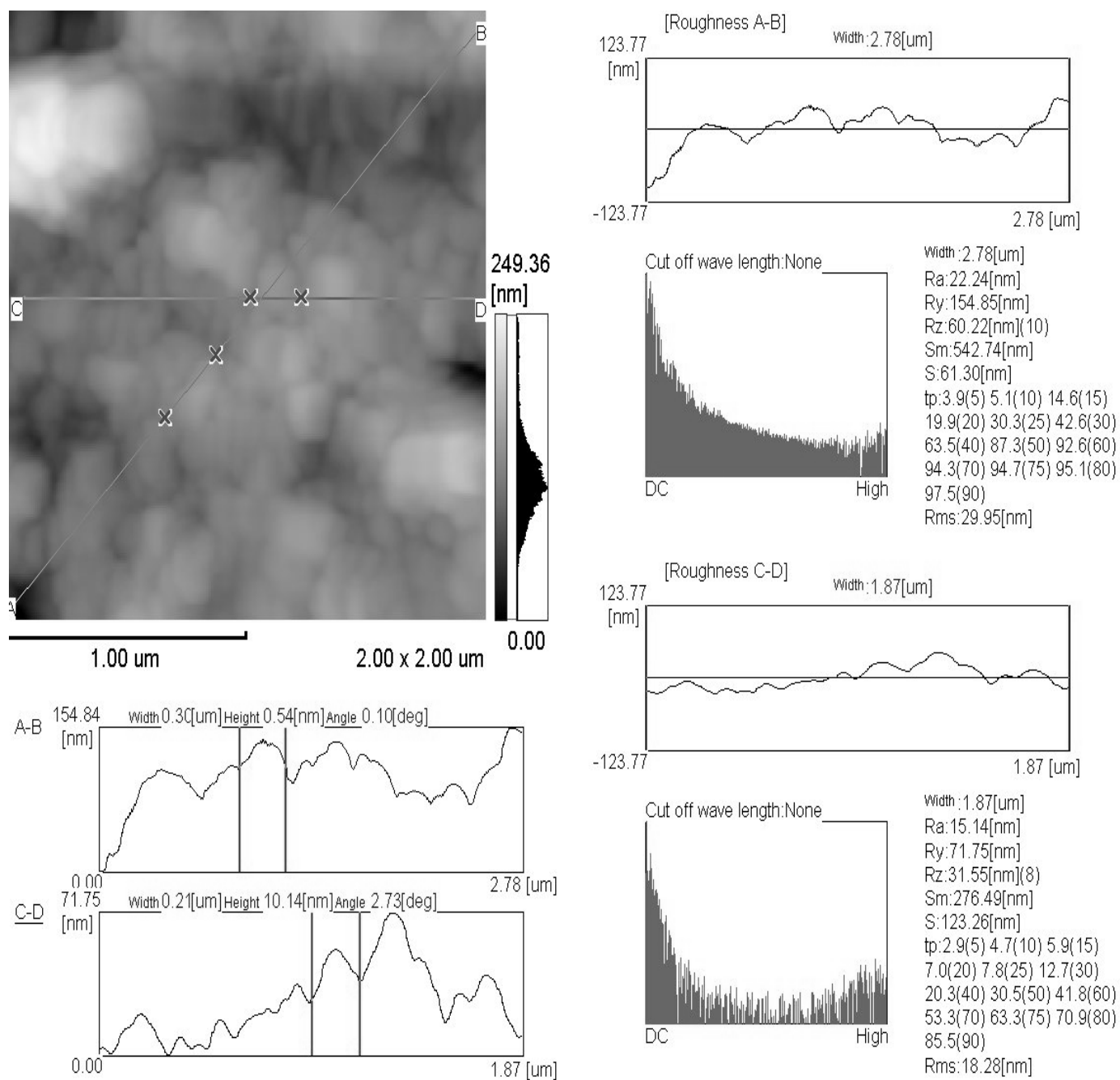

Fig. 8: Line analysis by AFM of TiN-coated carbon steel at 100 sccm nitrogen gas flow rate

\subsection{Adhesion}

The film-to-substrate adhesion strength was measured quantitatively using a scratch tester. A diamond indenter (Rockwell type) of $200 \mu \mathrm{m}$ radius applied an initial load $0.9 \mathrm{~N}$ onto a sample. The sliding velocity was $0.35 \mathrm{~mm} / \mathrm{min}$. The load was increased gradually by $7.27 \mathrm{mN} / \mathrm{min}$. Scratch length during scratch was $5 \mathrm{~mm}$. In the scratch test, critical load, Lc, could be used to calculate the adhesion strength. In order to obtain the magnitude of the critical load, acoustic signal, friction curve and microscope observation were utilized. Acoustic signal produced by the delamination of the film could be used to characterize the critical load; Lc. Scratch adhesion testing was performed on a coated sample to measure the critical load (Lc1). Four various images with various critical loads are shown in Fig. 9(a-d). These images, basically showing the character of failure of TiN-coated coating on CS. 
Jacobs et al. [25] has identified four main failure events for TiN coatings on HSS coupons: longitudinal cracks at the track edges (Lc1), semicircular coating cracks inside the scratch tracks (Lc2), cohesive chipping at the tracks edges (Lc3), and spallation at the track edges (Lc4). When the normal load applied on the indenter increases, plough-like channels appear in the scratch trace. Cracks originate from the plough-like channel and spread with the increasing loads. As cracks expand gradually with increasing load, cracks between two plough-like channels converge, thereby leading to cohesive chipping and later on spallation at the track edges, and then finally the coating is subject to complete failure/delamination. When the load increases gradually, the film delaminates from the substrate at the margins of the scratch trace.

Tang et al. [26] observed two types of scratch modes in TiN coatings deposited on GCR 15bearing steel using plasma immersion ion implantation and deposition technique.

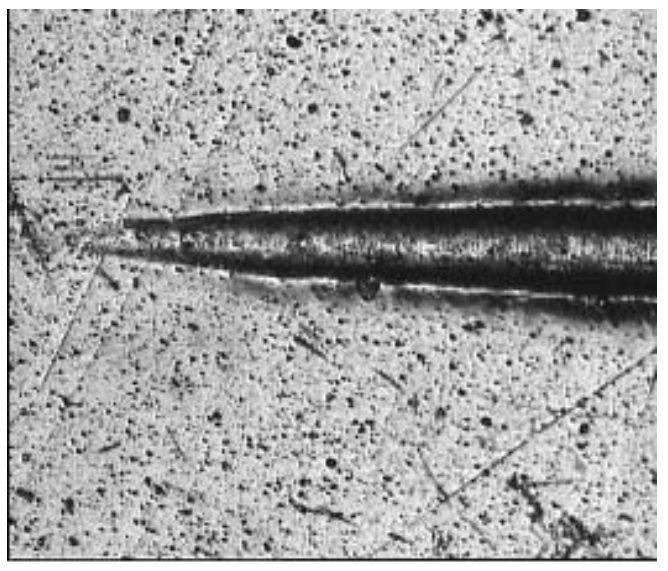

(a) $\mathrm{Lc} 1=10 \mathrm{~N}$ (plough like channel)

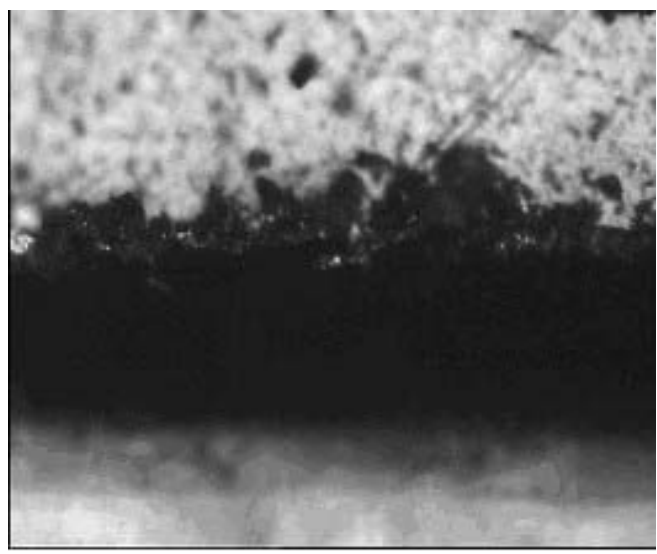

(c) Lc3 $=40 \mathrm{~N}$ (cohesive chipping/spallation)

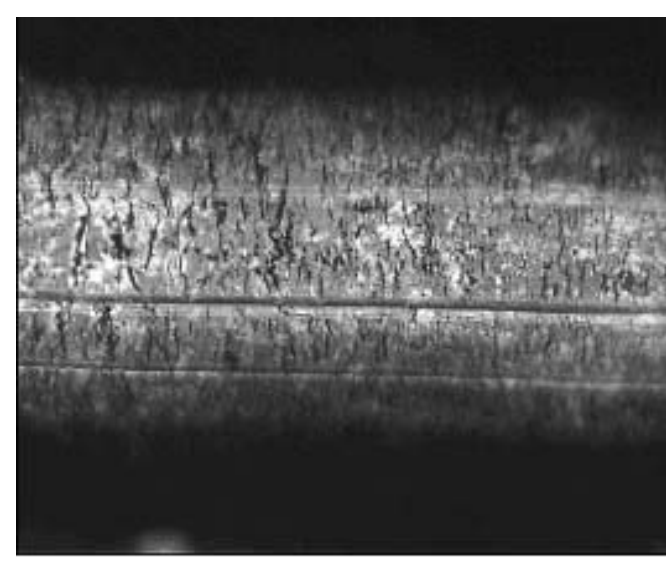

(b) $\mathrm{Lc} 2=40 \mathrm{~N}$ (semicircular coating cracks)

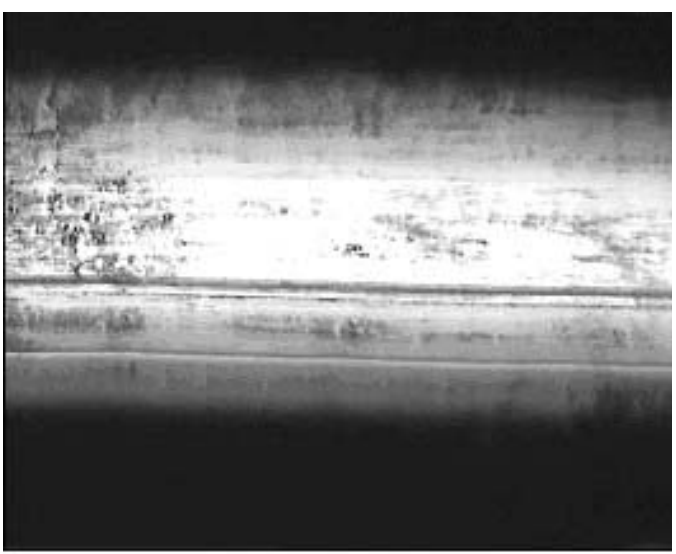

(d) Lc4 $=57 \mathrm{~N}$ (failure/delamination)

Fig. 9: Scratch trace of crack taken from CSM-Revetest for the coating deposited at $200 \mathrm{sccm}$ nitrogen gas flow rate

\section{CONCLUSIONS}

The objective of this present work is to see the effect of nitrogen gas flow rates in the range of $100-200 \mathrm{sccm}$ in TiN-deposited coating on carbon steel using the CAE technique. SEM images showed uniform and dense coating with substrate. Macroparticles of cathode material decreased 
by increasing nitrogen gas flow rate. From XRD-Patterns, a main peak $[1,1,1]$ can clearly be seen, indicating fcc crystal structure. The microhardness of the TiN-coated material showed about six times the increase in hardness compared to the uncoated sample. Surface roughness of deposited coating decreased with an increase in nitrogen gas flow rates. The AFM is a powerful technique for surface characterization, whose importance relies on its resolution power, allowing the acquisition of topographic images of the surface with nanometric resolution. Surface roughness measured by surface roughness tester and AFM show similar trend. Maximum adhesion strength of coating was noted at critical load of $40 \mathrm{~N}(200 \mathrm{sccm})$.

\section{ACKNOWLEDGEMENT}

This work has been financed by the Government of Malaysia under award letter No. JPA (L) KD333487 (MTCP) and the Ministry of Science, Technology and Innovation of Malaysia for the IRPA funding Project No. 03-02-06-0067 SR0006/06-02. Mubarak Ali would like to express his gratitude to Dr. Parvez Akhter, Director General Pakistan Council of Renewable Energy Technologies (Ministry of Science and Technology, Government of Pakistan) for his continual support.

\section{REFERENCES}

1. Matthews, A. and Lefkow, A.R. (1985), Problems in the physical vapor deposition of titanium nitride, Thin Solid Films, vol. 126, pp. 283-291.

2. Disatnic, G., Boxman, R.L., and Goldsmith, S. (1987), Characteristics of Macroparticle Emission from a High-Current-Density Multi-Cathode Spot Vacuum Arc, IEEE Trans. Plasma Sci., PS-15, pp. 520-523.

3. Bernard Coll, F. and David Sanders, M. (1996), Design of vacuum arc-based sources, Surf. Coat. Technol., vol. 81, pp. 42-51.

4. David Sanders, M. and André Anders (2000), Review of cathodic arc deposition technology at the start of the new millennium, Surf. Coat. Technol., vol. 133-134, pp. 78-90.

5. Martin, P.J. and Bendavid, A. (2001), Review of the filtered vacuum arc process and materials deposition, Thin Solid Films, vol. 394, pp. 1-15.

6. Petrov, I., Losbichler, P., Bergstrom, D., Greene, J.E., Münz, W.-D., Hurkmans, T., and Trinh, T. (1997), Ion-assisted growth of $\mathrm{Ti}_{1-x} \mathrm{Al}_{x} \mathrm{~N} / \mathrm{Ti}_{1-y} \mathrm{Nb}_{y} \mathrm{~N}$ multilayers by combined cathodic-arc/magnetron-sputter deposition, Thin Solid Films, vol. 302, pp. 179-192.

7. Huang, T.C. (1990), In; Barrett, C.S. et al. Advances in X-Ray Analysis, vol. 33, Plenum, New York, p. 91.

8. Toth, L.E. (1971), Transition Metal Carbides and Nitrides. In: Academic, New York, p. 31.

9. Baouchi, A.W. and Perry, A.J. (1991), A study of the macroparticle distribution in cathodicarc-evaporated TiN films, Surf. Coat. Technol., vol. 49(1-3), pp. 253-257.

10. Mattox, D.M. (1998), Handbook of Physical Vapor Deposition (PVD) Processing, Noyles Publications, Westwood, New Jersey, USA.

11. Takikawa, H., Kawakami, T., and Sakakibara, T. (1999), $\mathrm{N}_{2}$ Gas Absorption in Cathodic Arc Apparatus with an Al Cathode under Medium Vacuum, IEEE Trans. Plasma Sci., vol. 27(4), pp. 1034-1038.

12. Mustapha, N.M. and Howson, R.P. (2001), Reactive filtered arc evaporation Vacuum, vol. 60, pp. 361-368. 
13. Curtins, H. (1995), PLATIT: A new industrial approach to cathodic arc coating technology, Surf. Coat. Technol., vol. 76-77, pp. 632-639.

14. Gao Wei-Min, Christ Glorieux, Walter Lauriks, and Jan Thoen (2002), Investigation of titanium nitride coating by broadband laser ultrasonic spectroscopy, Chinese Physics, vol. 11, pp. 132-139.

15. Musil, J., Kadlec, S., Vyskocil, J., and Valvoda, V. (1988), New results in d.c. Reactive magnetron deposition of $\mathrm{TiN}_{x}$ films, Thin Solid Films, vol. 167, pp. 107-120.

16. Valvoda, V., Kuzel, R., Cerny, R., and Musil, J. (1988), Structure of TiN coatings deposited at relatively high rates and low temperatures by magnetron sputtering, Thin Solid Films, vol. 156 , pp. 53-64.

17. Musil, J. (2000), Hard and superhard nanocomposite coatings, Surf. Coat. Technol., vol. 125 , pp. 322-330.

18. Veprek, S. (1983), In: Pinard, P. and Kalbitzer, S. (Eds.), Proc. Mater. Res. Soc. Europe, Les éditions de physique, Les Ulis, France, p. 425.

19. Tavares, C.J., Rebouta, L., Alves, E., Cavaleiro, A., Rivière, J.P., and Declemy, A. (2000), A structural and mechanical analysis on PVD-grown (Ti,Al)N/Mo multilayers, Thin Solid Films, vol. 377-378, pp. 425-429.

20. Hovsepian, P.E., Lewis, D.B., Müunz, W.-D., Rouzaud, A., and Juliet, P. (1999), Chromium nitride/niobium nitride superlattice coatings deposited by combined cathodicarc/unbalanced magnetron technique, Surf. Coat. Technol., vol. 116-119, pp. 727-734.

21. Harris, S.G., Doyle, E.D., Wong, Y.-C., Munroe, P.R., Cairney, J.M., and Long, J.M. (2004), Reducing the macroparticle content of cathodic arc evaporation TiN coatings, Surf. Coat. Technol., vol. 183, pp. 283-294.

22. Golombek, K., Dobrzański, L.A., and Soković, M. (2004), Properties of the wear resistant coatings deposited on the cemented carbides substrates in the cathodic arc evaporation process, Journal of Materials Processing Technology, vol. 157-158, pp. 341-347.

23. Krim, J. and Palasantazas, G. (1995), Experimental observations of self-affine scaling and kinetic roughening at sub-micron length scales, Int. J. Mod. Phys. B9, pp. 599-632.

24. Chico, B., Martinez, L., and Pérez, F.J. (2005), Nitrogen ion implantation on stainless steel: AFM study of surface modification, Applied Surface Science, vol. 243, pp. 409-414.

25. Jacobs, R., Meneve, J., Dyson, G., Teer, D.G., Jennett, N.M., Harris, P., von Stebut, J., Comte, C., Feuchter, P., Cavaleiro, A., Ronkainen, H., Holmberg, K., Beck, U., Reiners, G., and Ingelbrechti, C.D. (2003), A certified reference material for the scratch test, Surf. Coat. Technol., vol. 174-175, pp. 1008-1013.

26. Baoyin Tang, Yuhang Wang, Langping Wang, Xiaofeng Wang, Hongxi Liu, Yonghao Yu, and Tao Sun (2004), Adhesion strength of TiN films synthesized on GCr15-bearing steel using plasma immersion ion implantation and deposition, Surf. Coat. Technol., vol. 186, pp. 153-156. 